\title{
Preliminary Thoughts on Crowded Air Travel and Consequent near Demands (your Eyes, as well as your Knees, are likely to be more Comfortable When Flying First Class)
}

\author{
Kenneth R Seger* \\ Associate Professor, Nova Southeastern University College of Optometry, United States
}

Submission: April 13, 2019; Published: April 23, 2019

*Corresponding author: Kenneth R Seger, Associate Professor, Nova Southeastern University College of Optometry 3200 South University Drive, Ft Lauderdale, Florida, United States

Keywords: Airlines; Delta; Investigation; Planes; Passengers; Reclining; Encroachment

\section{Opinion}

Airlines are trying to maximize their profits seemingly any way they can. Many formally free services are now only available for a fee. Fitting ever more passengers onto flights is a very significant income driver. This trend has led to publicized accounts of passenger disturbances over seat crowding and reclining seat encroachment [1].

Seat pitch is the distance between a point on a seat and the same one in front of it that's a rough approximation of legroom. For comparison, Delta Airlines has some first-class seats with 38-inch pitch $(96.5 \mathrm{~cm})$ [2]. When American Airlines launched the recently troubled Boeing 737, they originally considered shortening the seat space to 28 inches $(71 \mathrm{~cm})$. Due to an outcry in the travel industry they ended up setting their seat configuration with 30 -inch $(76 \mathrm{~cm})$ seat pitches for economy class [3]. Seat pitch has gone from an average of 32-35 inches $(81-89 \mathrm{~cm})$ in the $1990 \mathrm{~s}$ to $30-32$ inches $(76-81 \mathrm{~cm})$ in 2014 . Today the seat pitch is as low as 28 inches $(71 \mathrm{~cm})$. This paper is a preliminary investigation of accommodative demand for commercial airline passengers.

\section{Purpose}

As video screens (usually positioned in the seatback) are becoming ubiquitous on commercial airlines while more and more seats are being crowded into planes, passengers may be subjected to fairly onerous accommodative demands in order to see the video screens clearly.

\section{Methods}

Information on the seat pitch (distance between seats), seat height and amount of seat recline was obtained from the 3 main airplane manufacturers (Airbus, Boeing and Embraer), (It turns out seat pitch is not the manufacturer's doing, but how the individual airlines choose to configure the seating.) from airline websites, and from independent consumer sites. Based on the information and upon assumptions of average seatback thickness and the anterior-posterior head dimensions, accommodative demand was calculated for various seating and viewing scenarios.

\section{Results}

The accommodative demand created by video screens in eye-level position for economy seats ranges from 2.50D (for the most crowded seating arrangements) to $1.50 \mathrm{D}$. Business and first-class travelers have a maximum demand of 1.50D. Often it is less, as low as $0.75 \mathrm{D}$. The placement of the screens at eye-level is fine for non-presbyopia but requires an unusual head tilt for presbyopia to see it clearly. Increased accommodative demand only exacerbates the difficulty. The vergence system is also stressed by the unusual head position and the proximity of the viewing target.

Hand-held personal devices (phones, i-pads, Kindles), although allowing a more comfortable head position, give increased demand. If the passenger in front has their seat back, 
the personal device may be having to be held as close as $25 \mathrm{~cm}$, resulting in a $4 \mathrm{D}$ accommodative demand.

\section{Conclusion}

The calculated accommodative demand is not unreasonable for non-presbyopia's for all passenger conditions. For those wearing multi-focal spectacles designed for standard viewing, they either would have to tilt their head up to be able to use their add or be fortunate enough to have some useful residual accommodation. Especially for economy class passengers, moderate and higher presbyopia's are at risk for ocular asthenopia \&/or neck pain. IT may be prudent to consider single vision near only spectacles for frequent airplane travelers if they need to travel in economy or basic class.

\section{References}

1. (2014) Miami Herald.

2. (2018) Airways.

3. (2017) Airways magazine. 